\title{
Effects of Interferon Alpha $2 b$ on VEGFR-2, VEGFA, MAPK-1 and ERK-1 Gene Expression in Corneal Neovascularization Models
}

\author{
Mujdat Karabulut ${ }^{1}$, Harun Cakmak ${ }^{2}$, Gokay Bozkurt ${ }^{3}$, Sinem Karabulut ${ }^{1}$ \\ ${ }^{1}$ Department of Ophthalmology, Faculty of Medicine, Sttkı Koçman University, Muğla, Turkey \\ ${ }^{2}$ Department of Ophthalmology, Faculty of Medicine, Adnan Menderes University, Aydın, Turkey \\ ${ }^{3}$ Department of Medical Genetic, Faculty of Medicine, Adnan Menderes University, Aydın, Turkey \\ Email: mujdatkarabulut@gmail.com
}

How to cite this paper: Karabulut, M., Cakmak, H., Bozkurt, G. and Karabulut, S. (2018) Effects of Interferon Alpha 2b on VEGFR-2, VEGFA, MAPK-1 and ERK-1 Gene Expression in Corneal Neovascularization Models. Open Journal of Ophthalmology, 8, 97-105.

https://doi.org/10.4236/ojoph.2018.82014

Received: April 13, 2018

Accepted: May 15, 2018

Published: May 18, 2018

Copyright (ㅇ 2018 by authors and Scientific Research Publishing Inc. This work is licensed under the Creative Commons Attribution International License (CC BY 4.0).

http://creativecommons.org/licenses/by/4.0/

\begin{abstract}
AIM: To investigate effects of interferon alpha $2 \mathrm{~b}$ on vascular endothelial growth factor receptor-2 (VEGFR-2), vascular endothelial growth factor-A (VEGFA), mitogen activated protein kinase-1 (MAPK-1) and extracellular signal regulated kinase (ERK 1) gene expression in corneal neovascularization (CNV) modelsbyreal time polymerase chain reaction (PCR). METHODS: Thirty Wistar-Albino male rats were divided into three groups of ten rats each, and two corneas were obtained from each rat. CNV was induced by application of silver nitrate. In the first group one million $\mathrm{IU} / \mathrm{ml}$, in the second group three million IU/ml interferon-alfa $2 \mathrm{~b}$ and in the third (control) group isotonic saline was applied to both eyes two times a day for two weeks. Rats were sacrificed by cervical dislocation and corneas were used for real time polymerase chain reaction. RESULTS: MAPK-1 gene expression levels were significantly higher in both first and second groups compared to the control group ( $p=0.014$ and $p=0.008$, respectively). VEGFR-2 gene expression levels were found to be significantly higher in the second group than the control group ( $p=0.028)$. VEGFA gene expression levels were also significantly higher in the second group than the control group, and there was no difference between the control and first group and between first and second groups ( $p>$ 0.05). ERK gene expression levels did not differ among all groups $(\mathrm{p}=0.545)$. CONCLUSION: At the end of the study, it was shown that interferon-alfa $2 \mathrm{~b}$ does not inhibit VEGFR-2, VEGFA, MAPK-1 or ERK 1 gene expression in $\mathrm{CNV}$ models despite its known anti-VEGF activities.
\end{abstract}

\section{Keywords}

Corneal Neovascularization, Vascular Endothelial Growth Factor, 
Interferon-Alfa2b, Real Time Polymerase Chain Reaction

\section{Introduction}

The cornea is an avascular and translucent connective tissue which is located in the anterior portion of the eye and has refractive properties. Corneal neovascularization $(\mathrm{CNV})$ is an ocular pathology that has many etiologies, such as inflammatory, infectious, traumatic and degenerative disease, and can result in blindness if left untreated. Therefore, preventive and curative treatments are vitally important.

Although many methods have been tried, there is still no method found to be commonly effective. It is known that VEGF has a major role in CNV pathogenesis, so anti-VEGF agents are largely used.

Interferons are protein structures which support the immune system. Interferon-alpha $2 \mathrm{~b}$ (IFN- $\alpha 2 \mathrm{~b}$ ) has immunomodulatory actions and can inhibit viral replication by inducing gene transcription and changing cell surface antigen expression. It is widely used in chronic hepatitis B and C, neoplasms such as multiple myeloma, chronic myeloid leukemia, follicular lymphoma and carcinoid tumors.

In this study, we investigated whether IFN-alpha $2 b$ has an anti-VEGF effect at the level of gene expression, detected by real-time polymerase chain reaction (PCR).

\section{Materials and Methods}

This study was performed after permission of Adnan Menderes University Local Ethics Committee of Animal Research with the decision number $64583101 / 2013 / 094$ and is supported by Coordination Unit of the Research Projects with the decision number TPF-14028 dated on 24/03/2014.

\subsection{Animals and Treatment Groups}

Albino male rats $(250$ - $300 \mathrm{~g})$ kept in a light-dark $(12 \mathrm{~h}-12 \mathrm{~h})$ photoperiod in a temperature-controlled $\left(22^{\circ} \mathrm{C} \pm 0.5^{\circ} \mathrm{C}\right)$ room were fed with a standard diet and water ad libitum. All experiments were performed in accordance with the guidelines for animal research from the National Institutes of Health and were approved by the Committee of Animal Research at Adnan Menderes University.

Rats were randomly divided into three groups and experimental CNV was created for all groups. Experimental CNV was created with a silver nitrate stick, which causes burns in the cornea [1]. All corneal burns were created by the same researcher who was blind to all groups. After anesthesia, the silver nitrate sticks were applied for about 10 seconds to the central portion of corneas and the cornea was washed immediately with isotonic saline [2].

Then, in the first group one million IU/ml and in the second group three mil- 
lion IU/ml IFN- $\alpha 2 \mathrm{~b}$ was applied topically twice a day for two weeks, the control group received the same regimen of isotonic saline. IFN- $\alpha 2 b$ was prepared from Intron A 60 million IU solution for injection in a multidose pen by dilution with isotonic solution. The corneas were evaluated after silver nitrate stick application and at the end of the study with a "handheld biomicroscope". At the end of the study, the rats were sacrificed under ether anesthesia by cervical dislocation and corneas were removed. The right corneas were used for gene expression analysis by quantitative real time PCR.

\subsection{Real-Time PCR Analysis}

Total RNA from the eye was extracted using TRIzol reagent (Invitrogen) and purified with columns and reagents (Qiagen). cDNA was synthesized using a Roche cDNA synthesis kit. Primers for VEGFR-2, VEGFA, MAPK-1 and ERK were used for analysis using SYBR Green on a LightCycler 480 real-time PCR System (Roche Diagnostics, Indianapolis, IN) [3]. The cycle threshold (Ct) is defined as the number of cycles required for the fluorescent signal to cross the threshold in qPCR. The mRNA levels were calculated using the DCt method (target/reference, median).

\subsection{Statistical Analysis}

All data expressed as median Ct values $\pm \mathrm{SD}$. Kruskal-Wallis and Mann-Whitney $\mathrm{U}$ tests were used for analytic assessment of comparisons among groups. Values of $\mathrm{p}<0.05$ were regarded as significant.

\section{Results}

There was no animal loss until the end of the study. There was not any infiltration or inflammation after the injury and we did not need to use additional medication like antibiotics during the follow-up.

\section{Real-Time PCR}

\section{MAPK1 expression}

Real-time PCR was performed to determine the expression of MAPK1 mRNA. The mRNA expression level of MAPK1 was $0.00336 \pm 0.00163,0.00336 \pm$ 0.00140 and $0.00143 \pm 0.00037 \mathrm{Ct}$ in the first, second and control groups, respectively (Table 1).

In the control group, MAPK1 gene expression was significantly lower than the first and second groups $(p=0.014, p=0.008$, respectively). There was no significant difference between the first and second groups (Figure 1: Fold change for the control group).

\section{ERK expression}

The mRNA expression level of ERK was $0.000454 \pm 0.000226,0.000400 \pm$ 0.000316 and $0.000336 \pm 0.000131 \mathrm{Ct}$ in the first, second and control groups, respectively (Table 1$)$. There was no significant difference among all groups $(\mathrm{p}=$ 0.545) (Figure 2: Fold change for the control group). 
Table 1. Real-time PCR analysis.

\begin{tabular}{cccc}
\hline & $\begin{array}{c}\text { Control } \\
\text { (isotonic saline) }\end{array}$ & $\begin{array}{c}\text { First Group } \\
(1 \mathrm{million} \mathrm{IU/ml})\end{array}$ & $\begin{array}{c}\text { Second Group } \\
(3 \mathrm{million} \mathrm{IU/ml)}\end{array}$ \\
\hline Gene expression $(\mathrm{Ct})$ & & & \\
\hline MAPK 1 & $0.00143 \pm 0.00037$ & $0.00336 \pm 0.00163$ & $0.00336 \pm 0.00140$ \\
ERK & $0.000336 \pm 0.000131$ & $0.000454 \pm 0.000226$ & $0.000400 \pm 0.000316$ \\
VEGFR 2 & $0.000343 \pm 0.000240$ & $0.000470 \pm 0.000255$ & $0.000742 \pm 0.000442$ \\
\hline
\end{tabular}

\section{MAPK-1}

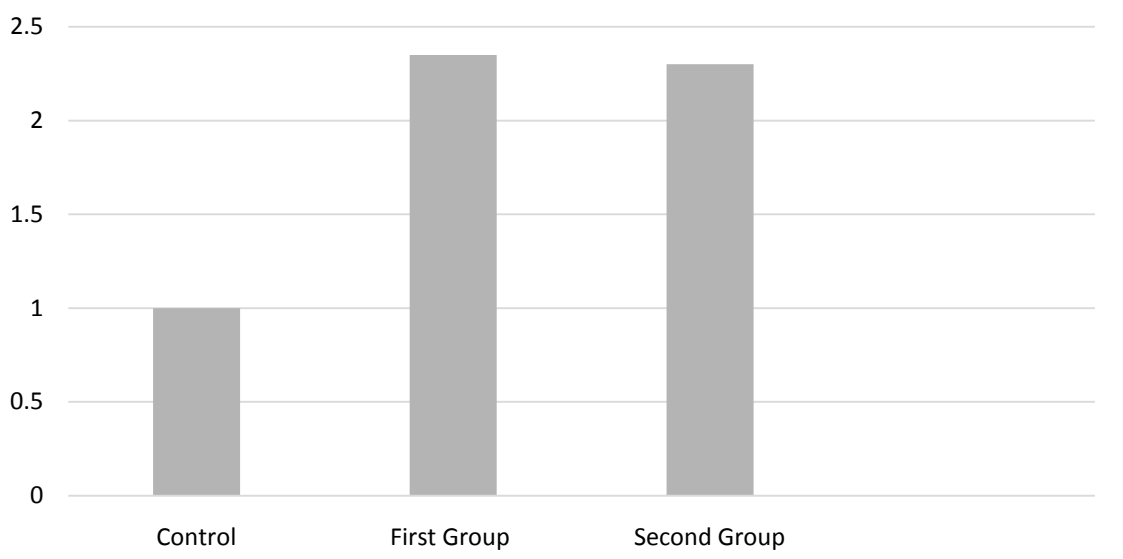

Figure 1. Mitogen-activated protein kinase 1 fold change for the control group.

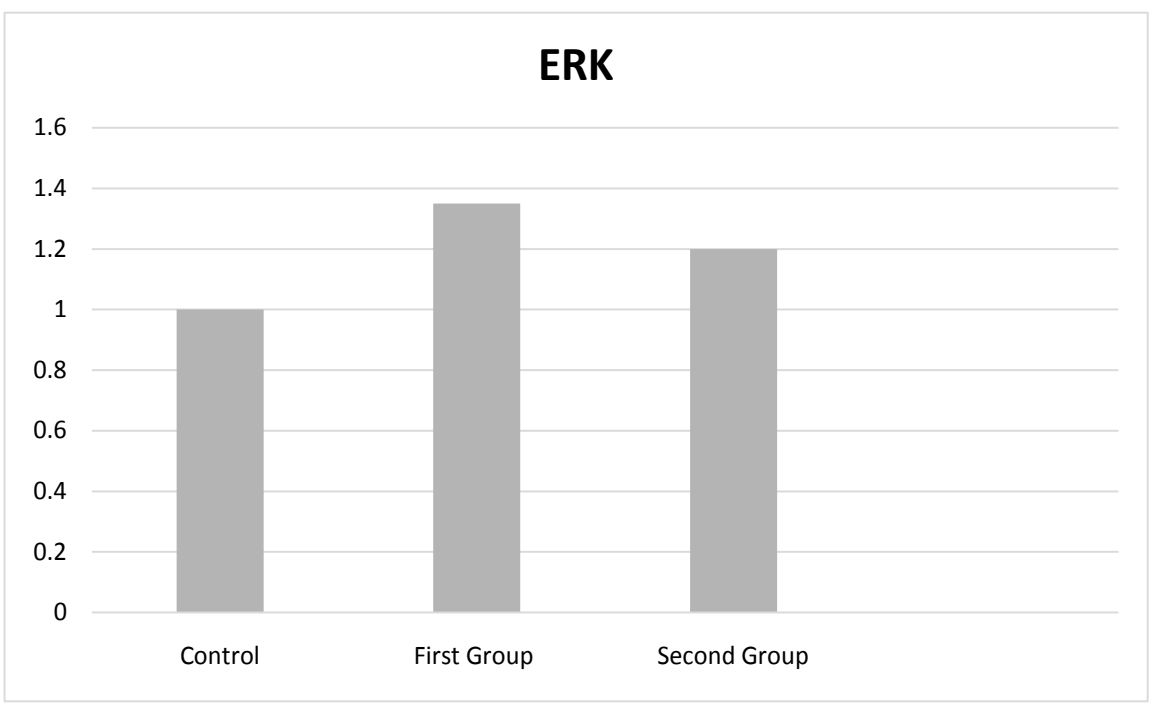

Figure 2. Extracellular signal-regulated kinases fold change for the control group.

\section{VEGFR 2 expression}

mRNA expression level of VEGFR 2 was $0.000470 \pm 0.000255,0.000742 \pm$ 0.000442 and $0.000343 \pm 0.000240 \mathrm{Ct}$ in the first, second and control groups, respectively (Table 1 ). In the second group, VEGFR 2 gene expression was significantly higher than the control group $(\mathrm{p}=0.028)$, but there were no differences 
between the first and second groups and between the first and control groups (Figure 3: Fold change for the control group).

\section{VEGFA expression}

In the second group, VEGFA gene expression was significantly higher than the control group ( $p \leq 0.05$ ), but there were no differences between the first and second groups and between the first and control groups (Figure 4: Fold change for the control group).

\section{Discussion}

The cornea is a translucent and avascular connective tissue and has mechanical barrier functions as well as refractive features. $\mathrm{CNV}$ is a corneal vascular pathology originating from the surrounding vascular plexus and has many etiological factors such as chemical burns, ischemia, infection, inflammation and trauma. It can cause blindness if left untreated. With loss of sight, it is an important public health problem affecting human life with physical, psychological and economic aspects [4] [5]. Thus, preventive and curative methods for CNV are crucial.

Although many treatment modalities have been tried for CNV, there is no common effective method. In the treatment of CNV, photodynamic therapy (FDT), laser photocoagulation, fine needle diathermy therapy, conjunctival-limbal and amniotic membrane transplantation (AMT) are commonly used in combination with medical treatments such as corticosteroids, non-steroidal anti-inflammatory drugs (NSAIDs) and immunomodulators. Unfortunately, the clinical efficacy of these treatment modalities is limited and may cause undesired side effects. To give an example, depending on the steroids prescribed, complications such as posterior subcapsular cataract (PSC), increased intraocular pressure and susceptibility to infections may occur.

\section{VEGFR-2}

2.5

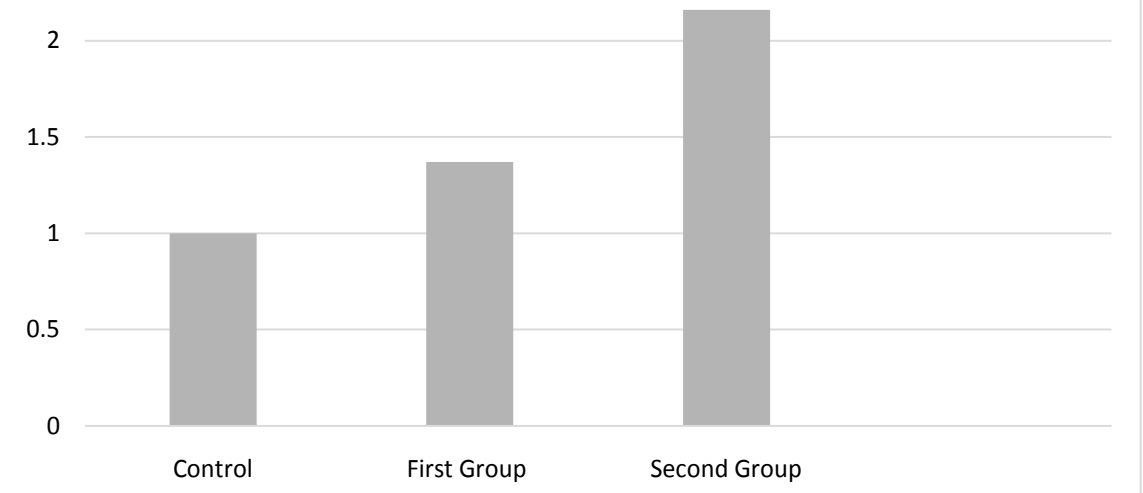

Fiugre 3. Vascular Endothelial Growth Factor Receptor 2 fold change for the control group. 


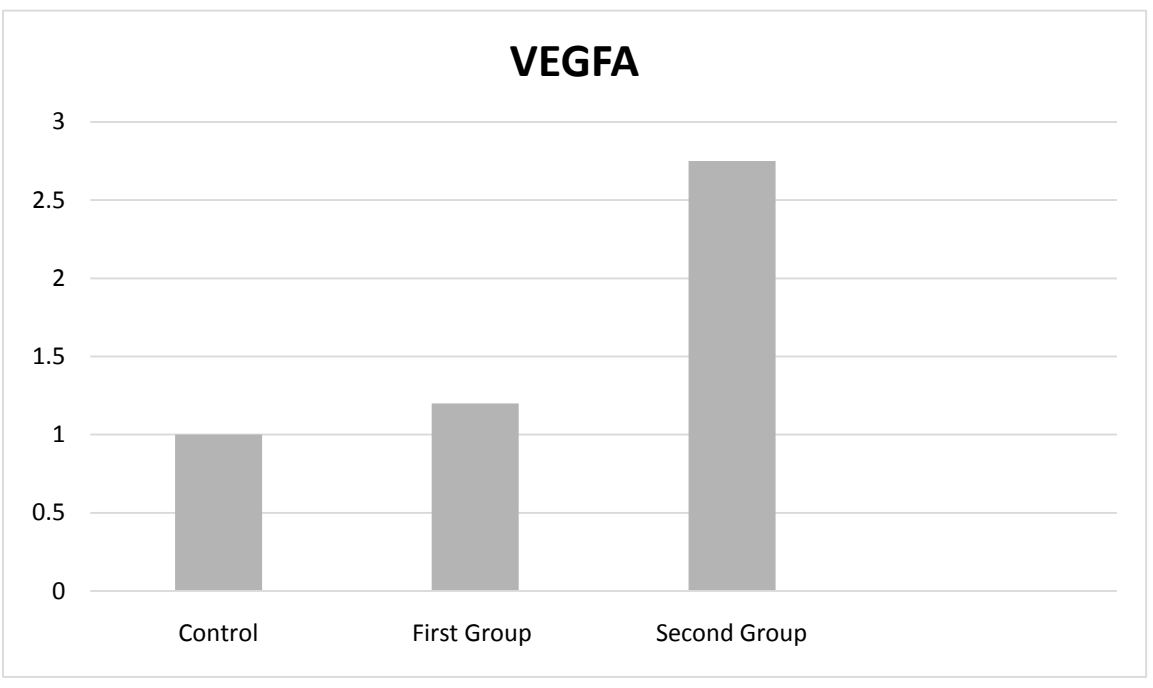

Figure 4. Vascular endothelial growth Factor A fold change for the control group.

Another treatment option for $\mathrm{CNV}$ is immunomodulator therapy. It has been thought that IL-1 receptor antagonists (IL-1ra) may inhibit CNV by modulating neutrophil and macrophage functions. Lu et al. reported that topical IL-1 receptor antagonists (IL-1ra) therapy was effective in CNV caused by alkaline burn [6].

Cyclosporine is another agent used in immunomodulatory therapy. In many animal studies it has been reported that cyclosporine can exhibit anti-angiogenic activity [7]. Likewise, in a clinical trial of seven cases with rheumatoid arthritis, clinical improvement was reported in CNV after topical cyclosporine use [8].

On the other hand, studies showing cyclosporine is ineffective for CNV have also been reported. For example, Bock et al. reported that cyclosporine treatment was not effective in penetrating keratoplasty induced CNV, and they thought that cyclosporine could give different results in human cornea [9].

It is also known that VEGF plays a major role in CNV, there has recently been a focus on therapeutic agents that directly block VEGF, VEGF-VEGFR interaction or VEGF synthesis pathways. Anti-VEGF agents are widely used in ocular diseases such as age-related macular degeneration (AMD), diabetic retinopathy (DRP), neovascular glaucoma (NGV) and retinal vascular pathologies [10].

One of these agents is the monoclonal humanized murine antibody bevacizumab (Avastin; Genentech/Roche). Bevacizumab can bind to all isoforms of VEGF and, indeed, has been approved for metastatic colorectal cancer by the US Food and Drug Administration (FDA) [11]. It has been used off label for CNV in topical, subconjunctival and intraocular forms. Hosseini et al. reported that subconjunctival bevacizumab is effective in alkaline burn induced corneal neovascularization in animal models [12]. In addition, Deli et al. reported that the use of bevacizumab seems to be an effective and safe method in the treatment of corneal neovascularization, either in the subconjunctival or topical application form [13]. 
The other anti-VEGF agent, ranibizumab (Lucentis; Genentech) is a fragment human monoclonal antibody and its affinity to VEGF is higher than bevacizumab. It is also thought that the systemic side effects are less due to less absorption into the bloodstream. In a prospective clinic study, Ferrari et al. reported that there was a significant reduction in the $\mathrm{CNV}$ area and vascular width with topical ranibizumab [14].

Besides agents that bind directly to VEGF, inhibitory activity on VEGF synthesis and VEGFR signaling pathways have also been tested. For instance, IFN-alpha $2 \mathrm{~b}$ is an antiviral drug discovered in the Charles Weissmann laboratory of the University of Zurich, and used in pathologies such as chronic hepatitis B and C, multiple myeloma and lymphoma. It was used for ocular superficial squamous neoplasia cases in topical and subconjunctival forms [15]. It has also been reported that IFN-alpha $2 \mathrm{~b}$ provided a remission rate of $96 \%$ in conjunctival intraepithelial neoplasia and appears to be an effective alternative treatment of noninvasive ocular surface squamous neoplasia and recurrent pterygium [16] [17] [18].

There is no ideal dose of IFN-alpha $2 \mathrm{~b}$ for ocular use yet. One million IU/ml and three million $\mathrm{IU} / \mathrm{ml}$ topical doses were compared in conjunctival intraepithelial neoplasia, but no significant difference was found in terms of effect or side effects [19].

Morlet et al. investigated the effect of topical INF-alpha $2 \mathrm{~b}$ in animal models after laser photo reflective keratectomy. INF-alpha $2 \mathrm{~b}$ was administered topically four times daily for five weeks, and they reported a significant reduction in corneal opacification [20].

Additionally, Nguyen et al. compared topical and subcutaneous INF-alpha with prednisolone acetate and reported that INF-alpha was not as effective as prednisolone acetate on $\mathrm{CNV}$ [21].

\section{Conclusion}

In this study, we found that IFN-alpha $2 \mathrm{~b}$ does not inhibit some of the agents involved in VEGF and VEGFR synthesis. This may result from many conditions such as short duration of the study, selection of subjects, transportation of samples and chemical substances used during transportation. Various results can be obtained by using different subjects and different study periods. Different animal models, duration of study or ambient conditions may result in different consequences.

\section{Foundation}

Supported by Adnan Menderes University Coordination Unit of the Research Projects with the decision number TPF-14028 dated on 24/03/2014.

\section{References}

[1] Mahoney, J.M. and Waterbury, L.D. (1985) Drug Effects on the Neovascularization Response to Silver Nitrate Cauterization of the Rat Cornea. Current Eye Research, 
4, 531-535. https://doi.org/10.3109/02713688508999984

[2] Mehrjardi, H.Z., Ghaffari, R., Mahbod, M. and Hashemi, H. (2014) Triamcinolone Acetonide as an Adjunct to Bevacizumab for Prevention of Corneal Neovascularization in a Rat Model. Journal of Ophthalmic and Vision Research, 9, 162-168.

[3] Seo, J.W., Chung, S.H., Choi, J.S. and Joo, C.K. (2012) Inhibition of Corneal Neovascularization in Rats by Systemic Administration of Sorafenib. Cornea, 31, 907-912. https://doi.org/10.1097/ICO.0b013e31823f8b9c

[4] Ambati, B.K., Patterson, E. and Jani, P. (2007) Soluble Vascular Endothelial Growth Factor Receptor-1 Contributes to the Corneal Antiangiogenic Barrier. British Journal of Ophthalmology, 91, 505-508. https://doi.org/10.1136/bjo.2006.107417

[5] Bock, F., Onderka, J., Dietrich, T., Bachmann, B., Pytowski, B. and Cursiefen, C. (2008) Blockade of VEGFR3 Signalling Specifically Inhibits Lymphangiogenesis in Inflammatory Corneal Neovascularisation. Graefe's Archive for Clinical and Experimental Ophthalmology, 246, 115-119. https://doi.org/10.1007/s00417-007-0683-5

[6] Lu, P., Li, L. and Liu, G. (2009) Enhanced Experimental Corneal Neovascularization along with Aberrant Angiogenic Factor Expressionin the Absence of IL-1 Receptor Antagonist. Investigative Ophthalmology \& Visual Science, 50, 4761-4768.

https://doi.org/10.1167/iovs.08-2732

[7] Bucak, Y.Y., Edurmus, M., Terzi, E.H., Kükner, A. and Çelebi, S. (2013) Inhibitory Effect of Topical Cyclosporin A \% 0.05 on Immune-Mediated Corneal Neovascularization in Rabbit. Graefe's Archive for Clinical and Experimental Ophthalmology, 251, 2555-2561. https://doi.org/10.1007/s00417-013-2467-4

[8] Gottsch, J.D. and Akpek, E.K. (2000) Topical Cyclosporin Stimulates Neovascularization in Resolving Sterile Rheumatoid Central Corneal Ulcers. Transactions of the American Ophthalmological Society, 98, 81-87.

[9] Bock, F., Matthaei, M. and Reinhard, T. (2014) High Dose Subconjunctival Cyclosporine A Implants Do Not Affect Corneal Neovascularization after High Risk Keratoplasty. Ophthalmology, 121, 1677-1682.

https://doi.org/10.1016/j.ophtha.2014.03.016

[10] Xu, J., Li, Y. and Hong, J. (2014) Progress of Anti-Vascular Endothelial Growth Factor Therapy for Ocular Neovascular Disease: Benefits and Challenges. Chinese Medical Journal, 127, 1550-1557.

[11] Ferrara, N., Hillan, K.J. and Novotny, W. (2005) Bevacizumab (Avastin), a Humanized Anti-VEGF Monoclonal Antibody for Cancer Therapy. Biochemical and Biophysical Research Communications, 333, 328-335. https://doi.org/10.1016/j.bbrc.2005.05.132

[12] Hosseini, H., Nejabat, M., Mehryar, M., Yazdchi, T., Sedaghat, A. and Noori, F. (2007) Bevacizumab Inhibits Corneal Neovascularization in an Alkali Burn Induced Model of Corneal Angiogenesis. Clinical \& Experimental Ophthalmology, 35, 745-748. https://doi.org/10.1111/j.1442-9071.2007.01572.x

[13] Deli, K., Magdalena, V., Katerina, L. and Pavel, S. (2014) Treatment of Corneal Neovascularization Using Anti-VEGF Bevacizumab. Journal of Ophthalmology, 10, 1155-1162.

[14] Ferrari, G., Dastjerdi, M.H. and Okanobo, A. (2013) Topical Ranibizumab as a Treatment of Corneal Neovascularization. Cornea, 32, 992-997. https://doi.org/10.1097/ICO.0b013e3182775f8d

[15] Boehm, M.D. and Huang, A.J. (2004) Treatment of Recurrent Corneal and Conjunctival Intraepithelial Neoplasia with Topical Interferon Alfa 2b. Ophthalmology, 111, 1755-1761. https://doi.org/10.1016/j.ophtha.2004.01.034 
[16] Schechter, B.A., Koreishi, A.F. and Karp, C.L. (2008) Long-Term Follow-Up of Conjunctival and Corneal İntraepithelial Neoplasia Treated with Topical İnterferon Alfa-2b. Ophthalmology, 115, 1291-1296. https://doi.org/10.1016/j.ophtha.2007.10.039

[17] Siamak, Z.G., Alizadeh, R. and Sophie, X.D. (2014) Topical Interferon Alpha-2b for Treatment of Noninvasive Ocular Surface Squamous Neoplasia with $360^{\circ}$ Limbal Involvement. Journal of Ophthalmic and Vision Research, 9, 423-426.

https://doi.org/10.4103/2008-322X.150811

[18] Mohammad, H.D., Hoda, G. and Esmat, D. (2015) Treatment of Recurrent Pterygium with Topical Administration of İnterferon Alpha-2b: A Case Report. Journal of Surgery and Trauma, 3, 30-32.

[19] Galor, A., Karp, C.L., Chhabra, S., Barnes, S. and Alfonso, E.C. (2010) Topical Interferon Alpha 2b Eye Drops for Treatment of Ocular Surface Squamous Neoplasia: A Dose Comparison Study. British Journal of Ophthalmology, 94, 551-554. https://doi.org/10.1136/bjo.2008.153197

[20] Morlet, N., Gillies, M.C., Crouch, R. and Maloof, A. (1993) Effect of Topical İnterferon-Alpha $2 \mathrm{~b}$ on Corneal Haze after Excimer Laser Photorefractive Keratectomy in Rabbits. Refractive Corneal Surgery, 9, 443-451.

[21] Nguyen, N., Goldberg, M., Pico, J., Kim, W., Abbott, R.L. and Levy, B. (1995) Topical and Subcutaneous Alpha-İnterferon Fails to Suppress Corneal Neovascularization. Cornea, 14, 147-151. https://doi.org/10.1097/00003226-199503000-00006 